\title{
Catalytic activity of Pd-Ni in the oxidation of hydrogen for the safety of nuclear power plant
}

\author{
Dariusz Lomot $^{1 *}$, Zbigniew Karpiński \\ ${ }^{1}$ Institute of Physical Chemistry PAS, Kasprzaka 44/52, 01-224 Warsaw, Poland \\ ${ }^{2}$ Cardinal Stefan Wyszyński University, Wóycickiego 1/3, 01-938 Warsaw, Poland \\ "Corresponding author: e-mail: dlomot@ichf.edu.pl
}

\begin{abstract}
$\mathrm{Pd}-\mathrm{Ni} / \mathrm{Al}_{2} \mathrm{O}_{3}$ systems were investigated in the reaction of hydrogen oxidation in terms of their possible application as catalysts used in passive autocatalytic recombiners (PARs) used in nuclear power plants. Testing experiments were carried out in a flowing system at different temperatures and humidity of the reaction mixture. The bimetallic catalysts exhibited higher response to the increase of temperature and higher resistance to inhibit water than the monometallic palladium catalyst. They showed excellent stability during a few tens of hours, similarly, like their monometallic counterpart. Our bimetallic catalysts of hydrogen oxidation can be used as cheaper alternatives to catalysts based on the precious metals in the hydrogen oxidation without loss of their activity over time.
\end{abstract}

Keywords: palladium, palladium-nickel, catalyst, hydrogen oxidation.

\section{INTRODUCTION}

The vital component of zircaloy, the construction material of the nuclear reactor equipment, is zirconium. This element is characterized by very low absorption of thermal neutrons and has high corrosion resistance, however at higher temperatures it reacts with water forming hydrogen. Hydrogen causes hydrogen embrittlement of fuel cladding for long lasting exposure and the risk of explosion during the reactor overheating. Hydrogen oxidation reaction plays a crucial role in safe removing of dangerous hydrogen from the nuclear reactor area, where passive autocatalytic recombiners (PARs) are used.

It is well known that platinum and palladium are the best catalytic metals for hydrogen oxidation. Other transition metals are also active but their performance is inferior to that of $\mathrm{Pt}$ and $\mathrm{Pd}^{\mathbf{1}, 2,3,4}$. Application of precious metals in passive autocatalytic recombiners must add to their overall cost. The natural thing is to search for cheaper effective alternatives to platinum and palladium. Because it cannot be reached by application of monometallic systems we decided to investigate bimetallic catalysts. We assumed that successful replacement of a considerable part of these noble metals (Pt, Pd) by some cheaper elements would definitely contribute to reduction of catalyst's cost. Testing such a possibility has prompted us to study the catalytic activity of Pd-Ni system in the oxidation of hydrogen. Although Pd-Ni alloys are practically completely miscible $f c c$ solids, it seems to be a general agreement that the surface layer of $\mathrm{Pd}-\mathrm{Ni}$ particles is highly enriched in palladium ${ }^{5,6}$. However, the underneath layer is composed of nearly pure nickel ${ }^{5}$. Both facts appear to be crucial in the genesis of our research. First, location of a more active alloy component in the surface layer should have a positive impact on its catalytic reactivity. Second, if the second layer is composed of mainly nickel, which differs from palladium by the atomic size, leading to a sandwich structure, then such surface layer should experience a considerable stress ${ }^{7}$. It was shown that this stress would positively modify catalytic properties of palladium ${ }^{8}$. Density functional theory calculations performed to study of $\mathrm{CO}$ oxidation on palladium and Pd-Ni alloys with sandwich structure demonstrated that partial replacement of palladium by cheaper nickel in the catalyst should lower activation energy of oxidation and reduce the cost of the catalyst ${ }^{9}$. Introduction of nickel to palladium catalysts makes a substantial impact on catalytic properties also in other types of chemical reactions, e.g. in catalytic reduction ${ }^{5,10,11}$ or in hydrodechlorination ${ }^{12,13}$.

In our work the catalytic behavior of $\mathrm{Pd}-\mathrm{Ni}$ in oxidation reactions was crucial, so the results of Kantalar Neyestanaki and Lindfors, where Pd-Ni/silica-fibre catalysts showed higher activity than $\mathrm{Pd} /$ silica-fibre catalyst in methane combustion ${ }^{11}$, were found particularly interesting. The interpretation of these results was based on the specific sandwiched assembly of $\mathrm{Pd} / \mathrm{Ni}$ surface where the stress generated by different atomic sizes of both metals modified the electronic structure ${ }^{11,14}$.

Our preliminary results showed that alumina-supported Pd-Ni catalysts would be regarded as respective replacements for expensive platinum or palladium catalysts for hydrogen oxidation ${ }^{15}$. This paper is an extension of the previous work. Here we focused on practical aspects of possible future application of Pd-Ni catalysts. To this aim we describe the results of long-term testing of $\mathrm{Pd}-\mathrm{Ni} /$ $\mathrm{Al}_{2} \mathrm{O}_{3}$ catalysts at higher conversions and their behavior in the reaction mixture characterized by a different degree of humidity. Both tests appear to be important prior to putting into practice new catalysts devoted for passive autocatalytic recombiners.

\section{EXPERIMENTAL}

\section{Catalyst preparation}

Preparation of $\mathrm{Pd} / \mathrm{Al}_{2} \mathrm{O}_{3}$ and $\mathrm{Pd}-\mathrm{Ni} / \mathrm{Al}_{2} \mathrm{O}_{3}$ catalysts was described elsewhere ${ }^{15}$. Briefly, the desired base catalyst $\left(2 \% \mathrm{Pd} / \mathrm{Al}_{2} \mathrm{O}_{3}\right)$ was prepared by dry impregnation of $\gamma$-alumina (Sasol Puralox Scca-150/200), precalcined at $350^{\circ} \mathrm{C}$ for $2 \mathrm{~h}$, with BET surface area $\sim 200 \mathrm{~m}^{2} / \mathrm{g}$ ) with acetylacetonate precursor $\mathrm{Pd}(\mathrm{acac})_{2}$ (Sigma-Aldrich, 99\%) dissolved in toluene. After impregnation, the wet material was dried at $120^{\circ} \mathrm{C}$, calcined in a flow of air at $400^{\circ} \mathrm{C}$, and reduced in $\mathrm{H}_{2}$ at $400^{\circ} \mathrm{C}$ for $4 \mathrm{~h}$. Following reduction, the catalyst was passivated in $\mathrm{H}_{2} \mathrm{O}$-saturated helium flow at room temperature for $24 \mathrm{~h}$ and purged in $\mathrm{He}$ for next $24 \mathrm{~h}$, and kept in a desiccator. The bimetallic 
catalysts $\left(2 \% \mathrm{Pd}-\mathrm{Ni} / \mathrm{Al}_{2} \mathrm{O}_{3}\right)$ were prepared by deposition of nickel particles on received monometallic catalyst as described earlier ${ }^{\mathbf{1 5}}$. To achieve intimate contact of both metals uncovered (i.e. not carrying Pd particles) alumina centres were blocked according to the procedure earlier described ${ }^{\mathbf{1 6}, \mathbf{1 7}^{17}}$. After adsorption of $\mathrm{H}_{2}$ at $70^{\circ} \mathrm{C}$, the base $\mathrm{Pd} / \mathrm{Al}_{2} \mathrm{O}_{3}$ catalyst was immersed in toluene and acetylacetone (puriss, Fluka), where acetylacetone was expected to block the surface of Pd-uncovered alumina, allowing subsequent deposition of nickel acetylacetonate (Sigma-Aldrich, 95\%) on previously anchored palladium species. After the deposition, calcination in air at $400^{\circ} \mathrm{C}$ for $2 \mathrm{~h}$, short purging in $\mathrm{He}$, and reduction in $\mathrm{H}_{2}$ at $400^{\circ} \mathrm{C}$ for $2 \mathrm{~h}$ were performed. Finally, the passivation with $\mathrm{He} / \mathrm{H}_{2} \mathrm{O}$ mixture was performed, followed by purging in $\mathrm{He}$ and drying as for the base catalyst mentioned above. A series of $\mathrm{Pd}-\mathrm{Ni} / \mathrm{Al}_{2} \mathrm{O}_{3}$ catalysts with $\mathrm{Pd}$ atomic contents of 70 , 80,90 and $100 \%$ were synthesized in the same manner.

\section{Catalyst characterization}

Characterization of $\mathrm{Pd} / \mathrm{Al}_{2} \mathrm{O}_{3}$ and $\mathrm{Pd}-\mathrm{Ni} / \mathrm{Al}_{2} \mathrm{O}_{3}$ catalysts was performed using XRD and TPR and described earlier ${ }^{15}$. The main conclusion from those studies was that the prepared and reduced $\mathrm{Pd}-\mathrm{Ni} / \mathrm{Al}_{2} \mathrm{O}_{3}$ catalysts were highly dispersed (metal particles of $2-4 \mathrm{~nm}$ in size) and both metals are well mixed ${ }^{\mathbf{1 5}}$. Table 1 recalls their basic characteristics.

Table 1. Composition of the catalysts

\begin{tabular}{|l|c|c|c|c|}
\hline Catalyst & Symbol & $\mathrm{Pd}[\mathrm{wt} \%]$ & $\mathrm{Ni}[\mathrm{wt} \%]$ & $\begin{array}{c}\text { Partice size } \\
{[\mathrm{nm}]}\end{array}$ \\
\hline $\mathrm{Pd} / \mathrm{Al}_{2} \mathrm{O}_{3}$ & $\mathrm{Pd} 100$ & 2.00 & 0 & 1.9 \\
\hline $\mathrm{Pd} 90 \mathrm{Ni} 10 / \mathrm{Al}_{2} \mathrm{O}_{3}$ & $\mathrm{Pd} 90$ & 2.00 & 0.122 & 2.6 \\
\hline $\mathrm{Pd} 80 \mathrm{Ni20} / \mathrm{Al}_{2} \mathrm{O}_{3}$ & $\mathrm{Pd} 80$ & 1.99 & 0.275 & 2.9 \\
\hline $\mathrm{Pd} 70 \mathrm{Ni30} / \mathrm{Al}_{2} \mathrm{O}_{3}$ & $\mathrm{Pd} 70$ & 1.99 & 0.470 & 3.7 \\
\hline
\end{tabular}

\section{Catalytic activity}

The catalytic recombination of hydrogen with oxygen from air was performed in a flowing system under atmospheric pressure, with the concentration of hydrogen beyond the explosion region ${ }^{18}$. The flow of reactant consisted of a mixture of $0.50 \% \mathrm{H}_{2}$ /synthetic air (analysis class 1 , from Linde) was regulated by a mass flow controller (Bronkhorst). The flow of the reaction mixture was $25 \mathrm{ml} \cdot \mathrm{min}^{-1}$, apart from the experiments with dry reaction mixture when the flow was $100 \mathrm{ml} \cdot \mathrm{min}^{-1}$. For experiments with wet reaction mixture, the reactant flow was permitted to pass through a saturator with water (bubbler), before entering the reactor.

Kinetic experiments at different partial pressures of water consisted of flowing the reaction mixture $(0.50 \%$ $\mathrm{H}_{2}$ /air) through the saturator with water maintained at a suitable temperature.

The catalyst $(\sim 100 \mathrm{mg})$ was deposited in a U-tube fitted with a fritted disc and thermocouple well. The course of hydrogen consumption was followed by a computer-controlled quadrupole mass spectrometer with electron multiplier (Ametek-Dymaxion). The reaction temperature was controlled with a temperature controller (Digi-Sense, Cole-Parmer) and recorded by the data collecting system of the mass spectrometer. Prior to the reaction, the samples were additionally reduced in $\mathrm{H}_{2}$ at $400^{\circ} \mathrm{C}$ for $0.5 \mathrm{~h}$, purged in $\mathrm{He}$ at the same temperature and cooled to room temperature. Then, the reaction runs were started and investigated over longer periods. For the experiments at wet conditions the reaction mixture (flow: $25 \mathrm{~mL} \cdot \mathrm{min}^{-1}$, space velocity: $0.03 \mathrm{~s}^{-1}$ ) was passing through a bubbler with water maintained at a selected temperature to ensure a proper partial pressure of water $(0.90,1.4,1.9,2.3 \mathrm{kPa})$. The progress of reaction was monitored by collecting the mass signal of hydrogen $(\mathrm{m} / \mathrm{z}=2)$. Consumption of hydrogen was calculated after subtraction of background signal from the vacuum chamber and taking as baseline signal out of the reactor. To check the catalyst stability at dry conditions at $25^{\circ} \mathrm{C}$, hydrogen consumption was checked at fixed intervals $(1,20,25,45,50$ and 70 hours from the start of the experiment). Next, experiments at higher temperatures were performed to check activity of $\mathrm{Pd}-\mathrm{Ni}$ catalysts at higher temperatures. Because of high activity of the examined catalyst, the higher flow of the reaction was used $\left(100 \mathrm{~mL} \cdot \mathrm{min}^{-1}\right.$, space velocity: $\left.0.1 \mathrm{~s}^{-1}\right)$ to ensure lower than $100 \%$ conversion. After setting the required temperature $\left(25,50,60\right.$ and $\left.70^{\circ} \mathrm{C}\right)$, the signals of hydrogen and temperature were collected. To present the inhibiting effect of water additional experiment was performed on the catalyst Pd90. First, the reaction mixture was passed over the dry catalyst, then additionally through the bubbler with water (2.3 $\mathrm{kPa}$, wet conditions) and again only through the catalyst with bypassing the bubbler (recovery of dry conditions).

\section{RESULTS AND DISCUSSION}

In this paper we wish to compare the activity of $\mathrm{Pd}-\mathrm{Ni}$ / $\mathrm{Al}_{2} \mathrm{O}_{3}$ catalysts with the monometallic $\mathrm{Pd} / \mathrm{Al}_{2} \mathrm{O}_{3}$ catalyst in the reaction of hydrogen oxidation at different wet conditions, check the long-term stability at dry conditions and activity at different reaction temperatures.

Basic characterization of the catalysts used here was presented in our previous report ${ }^{15}$. The synthesized $\mathrm{Pd}-$ $-\mathrm{Ni} / \mathrm{Al}_{2} \mathrm{O}_{3}$ catalysts reached high dispersion with metallic particles of 2-4 nm (recalled in Table 1) as measured by $\mathrm{H}_{2}$ chemisorption. Good intermixing of the active components was indicated by the temperature-programmed reduction (TPR) and X-ray diffraction studies ${ }^{15}$. In the TPR profiles, single bell-shaped profiles were observed at low reduction temperatures $\left(0-100^{\circ} \mathrm{C}\right)$ with an absence of negative peaks from a $\beta-\mathrm{PdH}$ phase decomposition suggesting good mixing of both metals and an apparent absence of unalloyed nickel species ${ }^{\mathbf{1 5}}$. This indicates that the applied catalyst preparation method led to deposition of both metals $(\mathrm{Pd}+\mathrm{Ni})$ in a close vicinity, allowing their alloying at the reduction conditions. On the other hand, catalyst calcination at $400^{\circ} \mathrm{C}$ does not cause any serious separation of both metals. In an opposite case, separated $\mathrm{Ni}$ (or $\mathrm{NiO}$ ) species would be transformed to $\mathrm{Ni}$ aluminate, which was not observed in the TPR spectrum $^{15}$.

Water as a product of the reaction as well as introduced with the reaction mixture inhibits the rate of recombination reaction ${ }^{2}$ which was confirmed by our experiments. The influence of humidity of the reaction mixture on reaction was explored by changing the partial pressure of water in the gas stream. It was found (Fig. 1) 


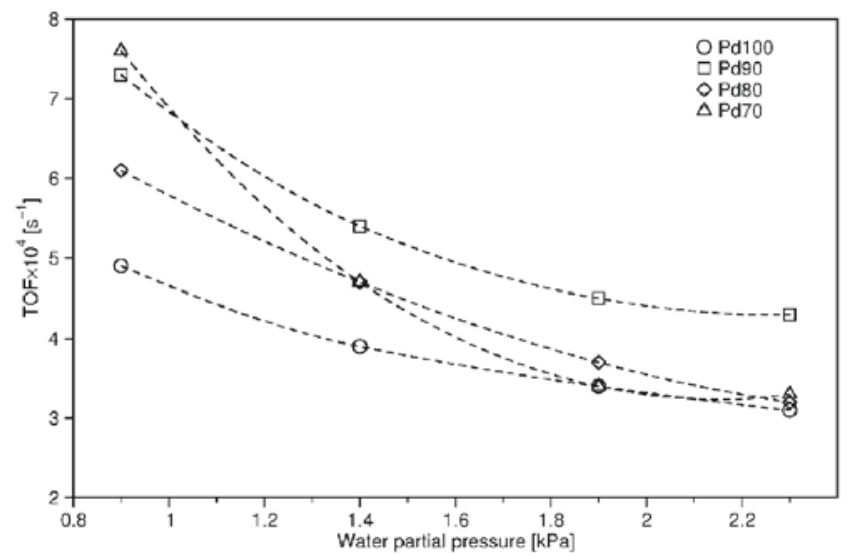

Figure 1. The effect of water partial pressure on the activity (TOF) of the catalysts in the reaction proceeded at $25^{\circ} \mathrm{C}$; flow of reaction mixture: $>25 \mathrm{~mL} \cdot \mathrm{min}^{-1}$

bimetallic catalysts, especially the catalyst with the lowest concentration of nickel (Pd90), exhibit higher resistance to water than palladium-only catalyst. Addition of nickel to palladium catalyst probably hinder the adsorption of water competing with hydrogen.

The inhibiting effect of water and recovery of the activity of bimetallic catalyst ( $\mathrm{Pd} 90)$ catalyst was presented on Figure 2, where the signal of hydrogen during switching the dry and wet reaction mixture through the catalyst is demonstrated. Valve turns to allow inflowing of the reactants to the reactor are marked with black triangles, whereas empty triangles indicate bypassing of the reactor. It is clear that the sharp negative minima ("spikes") in the signal $\mathrm{m} / \mathrm{z}=2$ are caused only by the first type of turns, not from bypassing of the reactor. The vertical bars show the consumption of hydrogen which is high at dry, low at wet conditions and becoming gradually higher after switching from wet to dry reaction mixture. Therefore, it appears that excess of water reduces the catalytic activity of Pd-Ni catalysts, however it is easily released from catalyst's surface at dry conditions, making the catalyst much more active. At dry conditions the consumption of hydrogen decrease asymptotically to almost constant value over $1 \mathrm{~h}$ reaction and with water (partial pressure: $2.3 \mathrm{kPa}$ ) in the reaction mixture this

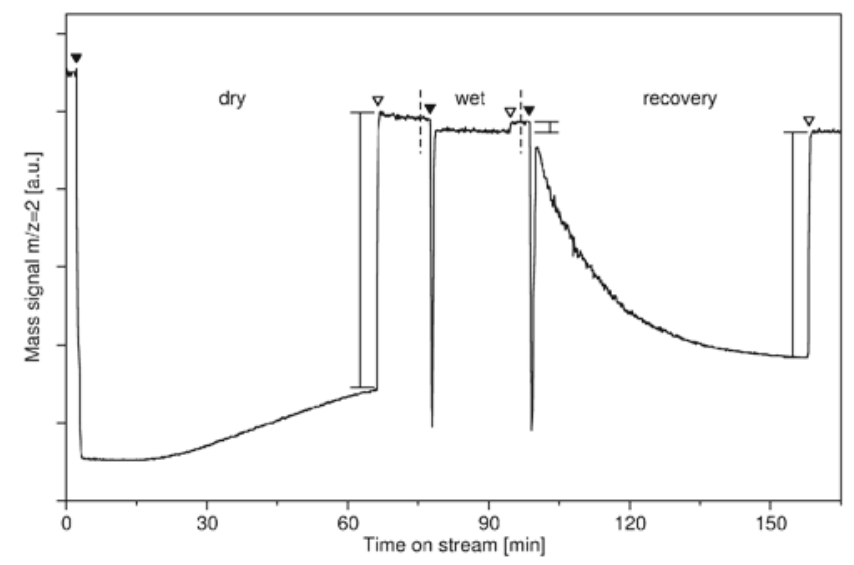

Figure 2. Mass signal of $\mathrm{H}_{2}(\mathrm{~m} / \mathrm{z}=2)$ during reaction in dry conditions, wet conditions and during drying (recovery of conversion) at $25^{\circ} \mathrm{C}$; flow of reaction mixture: $25 \mathrm{~mL} \cdot \mathrm{min}^{-1}$. Valves turns allowing the entrance of the reaction mixture the reactor are marked by filled triangles and valves turns to bypass by empty triangles. For explanation, see text consumption drastically drops to the low level. Then, at the dry reaction mixture a recovery of the conversion proceeds and catalyst after $1 \mathrm{~h}$ drying in the reaction mixture at room temperature returns to the almost initial hydrogen conversion.

Figure 3 shows the relation between the activity expressed in TOF and reaction temperature at dry conditions. We decided to investigate the performance of all tested catalysts at the conditions of high conversion. Such an approach does not allow to assess such kinetic parameters like reaction orders or activation energies, however it should allow to assess the practical value of $\mathrm{Pd}-\mathrm{Ni}$ catalysts. The activities of the tested catalysts at room temperature are similar, but at higher, more realistic reaction temperatures, the activity of the tested catalysts rises more steeply for bimetallic systems, especially for the most doped with nickel Pd-Ni catalyst (Fig. 3).

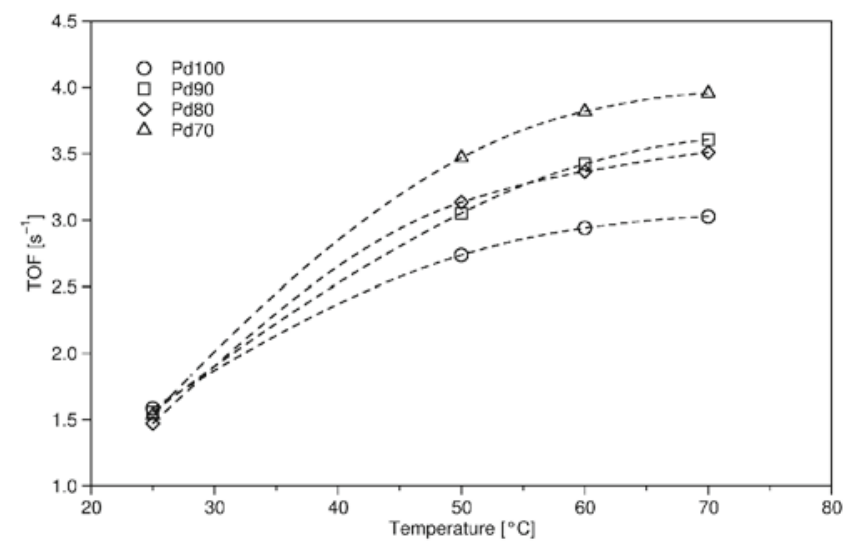

Figure 3. Activity (TOF) at dry conditions vs reaction temperature. Flow of reaction mixture $100 \mathrm{~mL} \cdot \mathrm{min}^{-1}$

The stability of our $\mathrm{Pd}-\mathrm{Ni} / \mathrm{Al}_{2} \mathrm{O}_{3}$ catalysts in comparison to $\mathrm{Pd} / \mathrm{Al}_{2} \mathrm{O}_{3}$ was checked at room temperature for 70 hours (Fig. 4) with probing the depletion of hydrogen in the reaction mixture stream at intermediate intervals. The bimetallic catalysts offer an excellent stability over time just as Pd-only catalyst but slightly lower conversion. Long lasting recombination reaction does not change catalytic worth of our bimetallic, cheaper, catalysts. Their conversions at room temperature reach $\sim 65 \%$ and this value is constant over time.

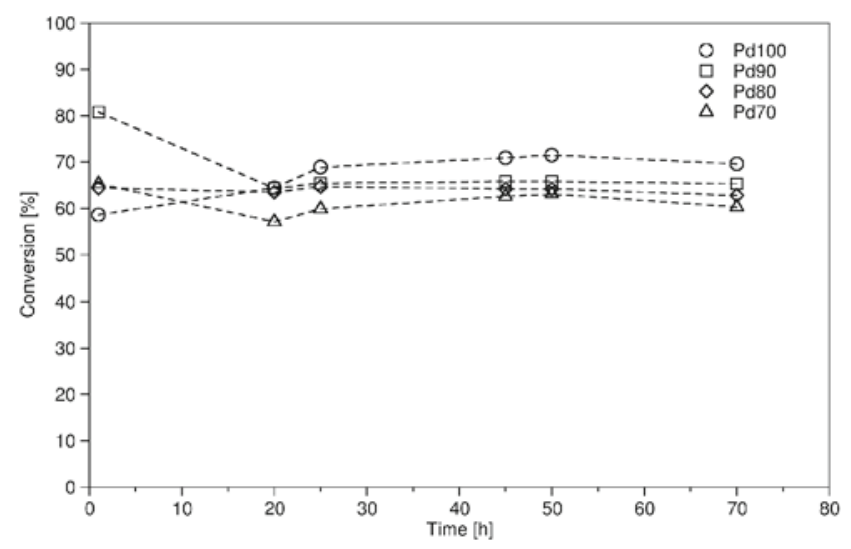

Figure 4. Stability of the catalysts with time on stream at $25^{\circ} \mathrm{C}$; flow of reaction mixture $25 \mathrm{~mL} \cdot \mathrm{min}^{-1}$ 


\section{CONCLUSIONS}

$\mathrm{Pd}-\mathrm{Ni} / \mathrm{Al}_{2} \mathrm{O}_{3}$ catalysts, prepared to achieve good metal alloying, showed high activity and stability over time in the recombination reaction of hydrogen and oxygen. Their excellent stability allows replacing of expensive precious-only catalysts in passive autocatalytic recombiners.

\section{ACKNOWLEDGMENT}

We thank research task No. 8 "Study of processes occurring under regular operation of water circulation systems in nuclear power plants with suggested actions aimed at upgrade of nuclear safety" financed by the National Research and Development Centre in the framework titled “Technologies Supporting Development of Safe Nuclear Power Engineering"

\section{LITERATURE CITED}

1. Hanson, F.V. \& Boudart, M. (1978). The reaction between $\mathrm{H}_{2}$ and $\mathrm{O}_{2}$ over supported platinum catalysts. J. Catal. 53, 56-67.

2. Jones, M.G. \& Nevell, T.G. (1990). Oxidation of hydrogen over supported palladium. J. Catal. 122, 219-229.

3. Boreskov, G.K. (1983). Catalytic activation of dioxygen. Cat. Sci. Techn. 3, 40-137.

4. Morfin, F., Sabroux, J.C. \& Renouprez, A. (2004). Catalytic combustion of hydrogen for mitigating hydrogen risk in case of a severe accident in a nuclear power plant: study of catalysts poisoning in a representative atmosphere. Appl. Catal. B-Environ 47, 47-58. DOI: 10.1016/j.apcatb.2003.07.001.

5. Rousset, J.L. \& Bertolini, J.C. (1996). Theory of segregation using the equivalent-medium approximation and bond-strength modifications at surfaces: Application to fcc Pd-X alloys. Phys. Rev. B 53, 4947-4957. DOI: 10.1103/PhysRevB.53.4947.

6. Helfensteyn, S., Luyten, J., Feyaerts, L. \& Creemers, C. (2003). Modelling surface phenomena in Pd-Ni alloys. Appl. Surf. Sci. 212/213, 844-849. DOI: 10.1016/S0169-4332(03)00088-6.

7. Bertolini J.C. (2000). Surface stress and chemical reactivity of Pt and Pd overlayers. Appl. Catal. A-Gen 191, 15-21.

8. Piccolo, L., Piednoir, A. \& Bertolini, J.C. (2005). Pd-Au single-crystal surfaces: Segregation properties and catalytic activity in the selective hydrogenation of 1,3-butadiene. Surf. Sci. 592, 169-181. DOI: 10.1016/j.susc.2005.07.005.

9. Lim, F.C.H., Zhang, J., Jin, H., Sullivan, M.B. \& Wu, P. (2013). A density functional theory study of CO oxidation on Pd-Ni alloy with sandwich structure. Appl. Catal. A-Gen 451, 79-85. DOI: 10.1016/j.apcata.2012.11.015.

10. Moss, R.L., Pope, D. \& Gibbens, H.R. (1977). Ethylene hydrogenation over nickel-palladium alloy films. J. Catal. 46, 204-213.

11. Hammer, B. (1998). Reactivity of a stepped surface O dissociation on Pd(211). Faraday Discuss. 110, 323-333. DOI: 10.1039/A801126E.

12. Śrębowata, A., Juszczyk, W., Kaszkur, Z. \& Karpiński, Z. (2007). Hydrodechlorination of 1,2-dichloroethane on active carbon supported palladium-nickel catalysts. Catal. Today 124, 28-35. DOI: 10.1016/j.cattod.2007.02.010.

13. Seshu Babu, N., Lingaiah, N. \& Sai Prasad, P.S. (2012). Characterization and reactivity of $\mathrm{Al}_{2} \mathrm{O}_{3}$ supported $\mathrm{Pd}-\mathrm{Ni}$ bimetallic catalysts for hydrodechlorination of chlorobenzene. Appl. Catal. B-Environ 111-112, 309-316. DOI: 10.1016/j. apcatb.2011.10.013.

14. Hammer, B. \& Nørskov, J.K. (2000). Theoretical surface science and catalysis-calculations and concepts. Adv. Catal. 45,71-129. DOI: 10.1016/S0360-0564(02)45013-4.

15. Łomot, D. \& Karpiński, Z. (2015). Hydrogen oxidation over alumina-supported palladium-nickel catalysts. Res. Chem. Intermed. 41, 9171-9179.DOI: 10.1007/s11164-015-1935-3.
16. Womes, M., Cholley, T., Le Peltier, F., Morin, S., Didillon, B. \& Szydlowski-Schildknecht, N. (2005). Study of the reaction mechanisms between $\mathrm{Pt}(\mathrm{acac})_{2}$ and alumina surface sites Application to a new refilling technique for the controlled variation of the particle size of $\mathrm{Pt} / \mathrm{Al}_{2} \mathrm{O}_{3}$ catalysts. Appl. Catal. A-Gen 283, 9-22. DOI:10.1016/j.apcata.2004.12.030.

17. Latusek, M.P., Heimerl R.M., Spigarelli, B.P. \& Holles, J.H. (2009). Synthesis and characterization of supported bimetallic overlayer catalysts. Appl. Catal. A-Gen 358, 79-87. DOI: 10.1016/j.apcata.2009.01.038.

18. Heck, R., Kelber, G., Schmidt, K. \& Zimmer, H.J. (1995). Hydrogen reduction following severe accidents using the dual recombiner-igniter concept. Nucl. Eng. Des. 157, 311-319. 